\title{
Effect of Lime on the Compressibility Characteristics of a Highly Plastic Clay
}

\author{
İnci Süt-Ünver \\ Ph.D. Candidate \\ Department of Civil Engineering \\ Istanbul Technical University \\ Istanbul - Turkey \\ Musaffa Ayşen Lav \\ Prof. Dr. \\ Department of Civil Engineering \\ Istanbul Technical University \\ Istanbul - Turkey \\ Erdal Çokça \\ Prof. Dr. \\ Department of Civil Engineering \\ Middle East Technical University \\ Ankara - Turkey
}

\begin{abstract}
Soils with high plasticity can become highly compressible depending on the parameter compression index. Same type of soils can have also heaving potential depending on the expansion index. These type of highly plastic clays can be improved by adding chemical stabilizers such as lime. In this study, soil samples that are extremely highly plastic have been taken from clay deposits of Ankara in Turkey. Hydrated lime has been used as a chemical stabilizer. Firstly, reference tests have been carried out on natural soil samples. Then the clay is mixed with the lime agent at different percentages of dry weight of the soil (1\%, 3\%, 5\%, 7\% and 9\%) and compressibility characteristics of the improved soil samples have been determined. All of the results are evaluated and the changes in compressibility and expansion characteristics have been interpreted in this paper. Optimum values have been found for both compression and expansion indices.
\end{abstract}

Keywords: highly plastic clay, lime treatment, odometer test, compression index, expansion index

\section{Introduction}

Highly plastic clays are generally quite compressible depending on the parameter compression index $\left(\mathrm{C}_{\mathrm{c}}\right)$ which can be found by odometer tests in laboratory. Void ratio (e) versus effective stress $\left(\sigma^{\prime}\right)$ graph is prepared first by using the results of odometer tests. Void ratio (e) versus $\log \left(\sigma^{\prime}\right)$ graph can be drawn then so that plots can be approximated to straight lines. Both compression and expansion part of the test can be monitored to get compression and expansion indices from the slopes of the straight lines. $\mathrm{C}_{\mathrm{c}}$ is the slope of the virgin compression line of the test. High value of $\mathrm{C}_{\mathrm{c}}$ means high compressibility. The expansion index $\left(\mathrm{C}_{\mathrm{e}}\right)$ is the slope of the unloading part of the test plot. In the same way, the higher the $\mathrm{C}_{\mathrm{e}}$ value, the higher the expansion capacity of the clay. The compressibility and expansion potential of highly plastic clays cause problems in foundation engineering applications. There are several stabilization methods to improve the highly plastic clays. Lime stabilization is one of the popular method for this purpose.

In this study, disturbed soil samples have been taken from the site of Bilkent Atatürk Hospital district of Ankara, near Ankara-Eskişehir State Highway in Turkey. In order to identify the natural soil, reference tests were performed and as a result of these tests soil samples are classified as highly plastic (plasticity index, PI=76\%). And also clay fraction of the soil has been determined as $45 \%$. Therefore, the activity is $1.69(\mathrm{~A}=1.69)$. The tested soils are called as Bilkent Clay in this paper. 
After the reference tests on untreated soils, the natural clay soils are mixed with the hydrated lime at different percentages of dry weight of the soil $(1 \%, 3 \%, 5 \%, 7 \%$ and $9 \%)$ and compressibility characteristics of the improved soil samples along with the untreated soil characteristics have been determined. Samples have been prepared at optimum water content and maximum dry density by means of Harvard miniature compaction test (Wilson, 1950, ASTM D698- 07). The odometer test results of a highly plastic clay with and without lime treatment process are evaluated in this paper. The effect of lime agent on the compressibility characteristics have been examined. Optimum values have been determined for compressibility and expansion.

\section{Properties of Bilkent Clay}

Experiments have been performed on remolded samples prepared at optimum water content $\left(\mathrm{w}_{\text {opt. }}\right)$ and maximum dry density $\left(\gamma_{\text {drymax }}\right)$. Soil properties of the Bilkent Clay are given in Table 1 below. As seen in Table 1, the clay is highly plastic (plasticity index, $\mathrm{PI}=76 \%$ ). The fines content is around $80 \%$ which means that the silt and clay proportion of the soil samples is quite high. It has been found that the clay-size fraction of the soil is $45 \%$. Therefore, it can be inferred that the Bilkent Clay is quite active (i.e. activity, $A=76 / 45=1.69$ ). Compression and expansion indices of the remolded natural clay samples have been found as 0.405 and 0.094 respectively in odometer tests.

Table 1. Properties of Bilkent Clay

\begin{tabular}{|l|l|l|l|l|l|l|l|l|l|l|}
\hline \multicolumn{4}{|l|}{ Sieve Analysis } & \multicolumn{4}{|l|}{ Atterberg Limits } & \multicolumn{2}{l|}{ Proctor Test } & \multicolumn{2}{c|}{ Odometer Test } \\
\hline $\begin{array}{l}+ \text { No. } \\
\begin{array}{l}\text { No. } \\
(\%)\end{array}\end{array}$ & $\begin{array}{l}\text { Clay } \\
(\%)\end{array}$ & $\begin{array}{l}\text { Size } \\
(\%)\end{array}$ & $\begin{array}{l}\text { LL } \\
(\%)\end{array}$ & $\begin{array}{l}\text { PL } \\
(\%)\end{array}$ & $\begin{array}{l}\text { PI } \\
(\%)\end{array}$ & $\begin{array}{l}\text { SL } \\
(\%)\end{array}$ & $\begin{array}{c}\gamma_{\text {drymax }} \\
\left(\mathrm{g} / \mathrm{cm}^{3}\right)\end{array}$ & $\begin{array}{l}\mathrm{w}_{\text {opt }} \\
(\%)\end{array}$ & $\mathrm{C}_{\mathrm{c}}$ & $\mathrm{C}_{\mathrm{e}}$ \\
\hline 0.5 & 79.2 & 45 & 109 & 33 & 76 & 9 & 1.369 & 29 & 0.405 & 0.094 \\
\hline
\end{tabular}

Note: LL: Liquid Limit, PL: Plastic Limit, PI: Plasticity Index, SL: Shrinkage Limit, $C_{c}$ : Compression Index, $\mathrm{C}_{\mathrm{e}}$ : Expansion Index

\section{Lime Stabilization}

Lime is formed by the decomposition of limestone under extremely high temperatures. A chemical reaction occurs as a result of combination of lime with water and the soluble silica and alumina present in clay. This process results in the formation of new compounds. When combined with water, its primary function is the alteration of particle structure and increased resistance to shrink-swell and moisture susceptibility. A secondary result, on the other hand, is binding of particles when combined with clay. Strength gain is obtained by this process. Thus, cation exchange and flocculation-aglomeration phenomena result in short-term benefits. Pozzolanic reactions, on the other hand, are related with long-term stabilization.

The first phase of the chemical reaction involves immediate changes in soil texture and soil properties caused by cation exchange. The free calcium of the lime exchanges with the adsorbed cations of the clay mineral, resulting in reduction in size of the diffused water layer surrounding the clay particles. This reduction in the diffused water layer allows the clay particles to come into closer contact with one another, causing flocculation-agglomeration of the clay particles, which transforms the clay into a more silt-like and sand-like material. Overall, the flocculation and agglomeration phase of lime stabilization results in a soil that is more readily mixable, workable, and, ultimately, compactable (Eades and Grim, 1960).

The second phase of the chemical reaction involves pozzolanic reactions within the lime-soil mixture, resulting in strength gain over time. When lime is combined with a clay soil, the $\mathrm{pH}$ of the pore water increases. When the $\mathrm{pH}$ reaches 12.4, the silica and alumina from the clay become soluble and are released from the clay mineral. In turn, the released silica and alumina react with the calcium from the lime to form cement, which strengthens in a gradual process that continues for several years (Eades and Grim, 1960).

\section{Odometer Tests}

Odometer tests were conducted in accordance with ASTM D 2435-96. Test samples are placed in $6 \mathrm{~cm}$ height rings. The inner diameter of these rings is $63.5 \mathrm{~mm}$ and the outer diameter is $83.4 \mathrm{~mm}$. Samples are subjected to time-dependent loading during odometer testing. A seating load of $5 \mathrm{kPa}$ is applied at the beginning of the test to provide an appropriate contact between top cap and porous stone. 
The maximum pressure applied in this study was $1600 \mathrm{kPa}$ in order to see the consolidation behavior at large loads. Vertical static loads of $25,50,100,200,400,800$ and $1600 \mathrm{kPa}$ with a load increment ratio of $\Delta \sigma / \sigma=1.0$ (where $\Delta \sigma=$ increase in pressure and $\sigma=$ pressure before the increase) are applied to all samples. The unloading is performed using the steps, 400,100 and $25 \mathrm{kPa}$.

\section{Results of Laboratory Experiments}

The e versus $\log \left(\sigma^{\prime}\right)$ graphs for all lime contents along with the natural soil's $(0 \%$ lime) graph are given in Figure 1. The $C_{c}$ and $C_{e}$ values with increasing lime content are given in Figure 2 and Figure 3 respectively. As understood from Figure 1, the slope of the virgin compression line (i.e. the $\mathrm{C}_{\mathrm{c}}$ value) of the natural soil (untreated soil) is relatively quite high. This means that the compressibility of the highly plastic natural clay is also relatively quite high. The odometer tests for lime-treated clays show that the $1 \%$ and $3 \%$ lime contents are not effective to decrease the compressibility. The compressibility of the samples decreases considerably starting from $5 \%$ lime content (Figure 1 and Figure 2). Similar evaluations can be made for the slopes of the lines of the unloading part of the tests (i.e. the $\mathrm{C}_{\mathrm{e}}$ values). The $\mathrm{C}_{\mathrm{e}}$ values of the untreated samples are high as compared to treated samples' values. The lime contents of $3 \%$ to $5 \%$ especially seems quite effective to decrease the expansion index values (Figure 1 and Figure 3).

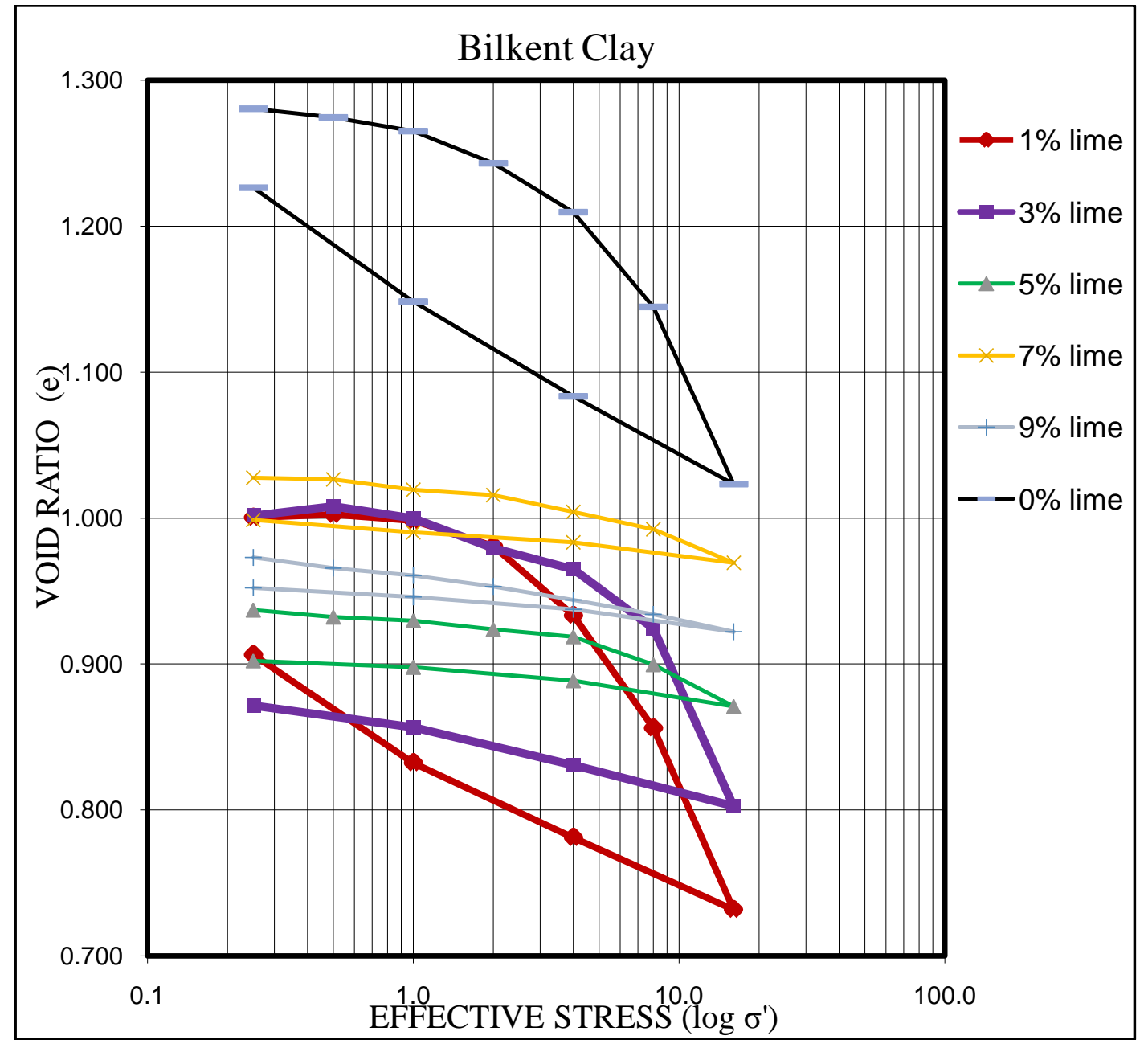

Figure 1: e- $\log \sigma^{\prime}$ relationship for natural and lime-treated soil samples of Bilkent Clay 


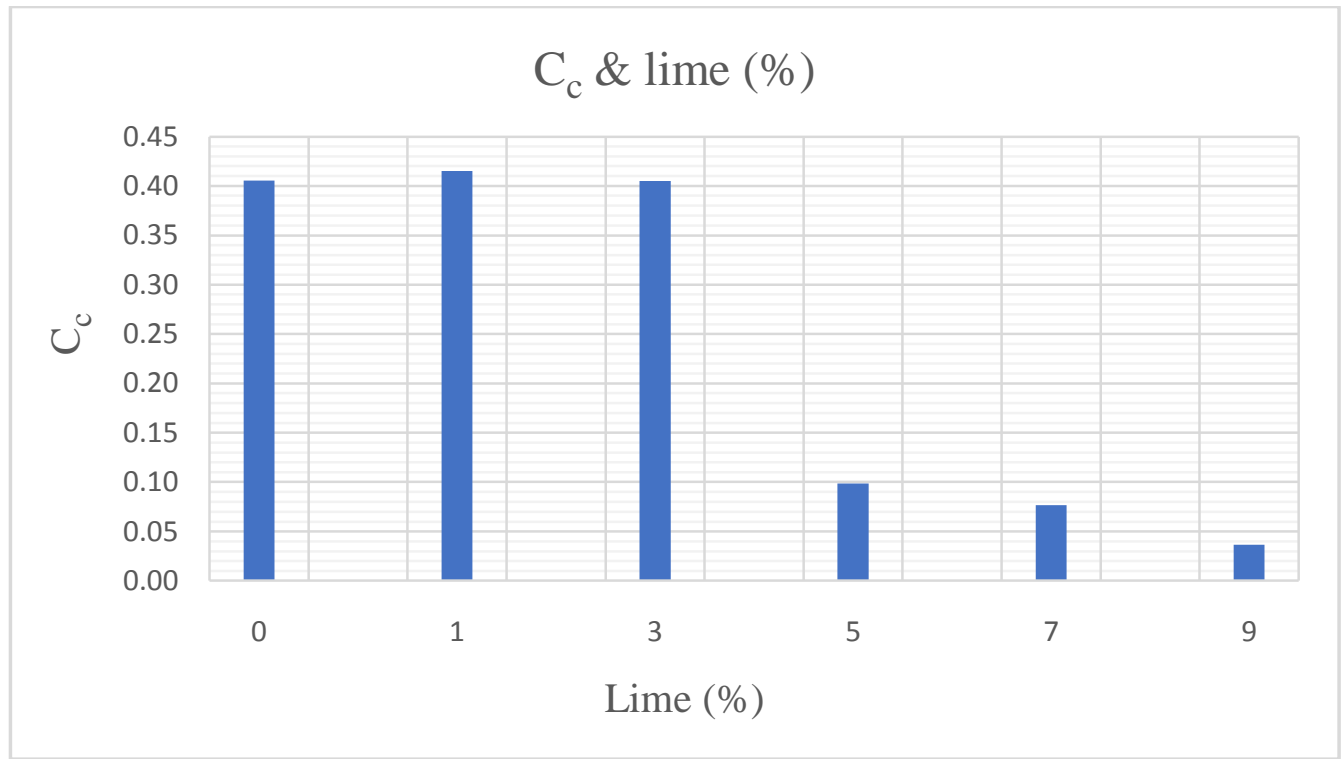

Figure 2: Compression index $\left(\mathrm{C}_{\mathrm{c}}\right)$ values with increasing lime content for Bilkent Clay

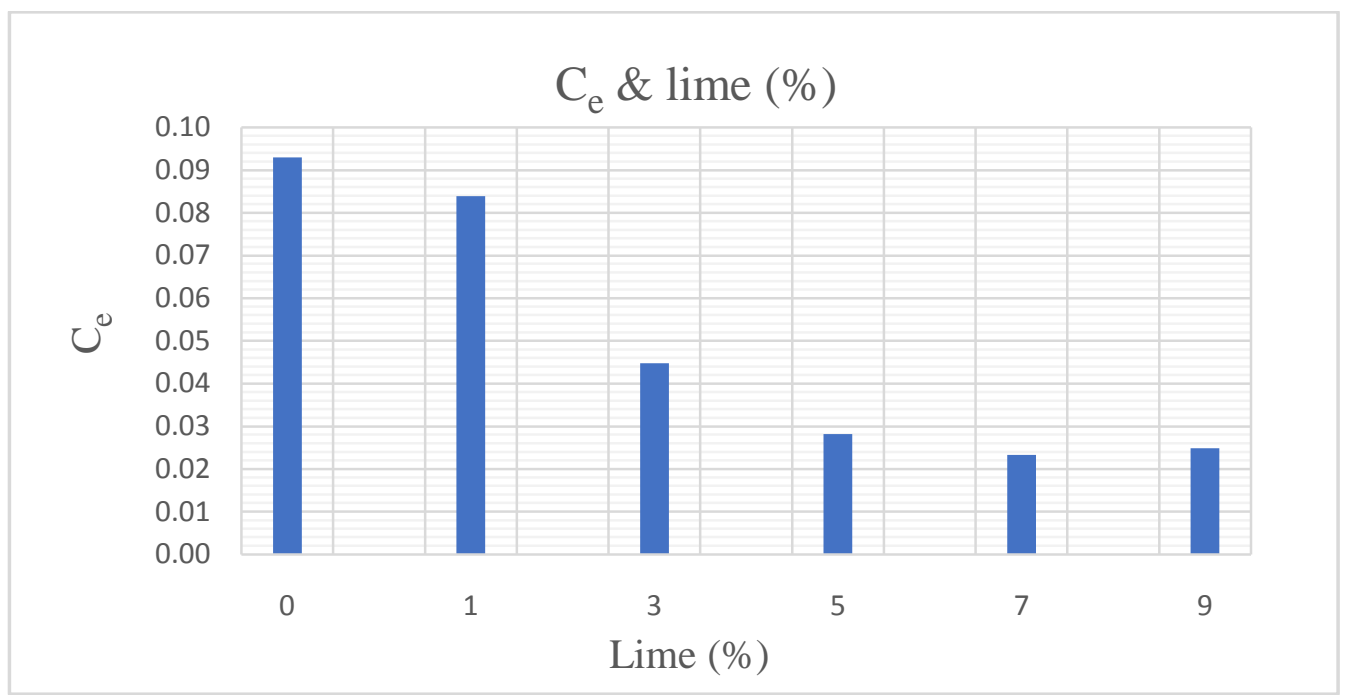

Figure 3: Expansion index $\left(C_{e}\right)$ values with increasing lime content for Bilkent Clay

\section{Conclusions}

A series of odometer tests were performed on lime-treated clay samples to determine the compressibility and expansion behavior of the samples. Highly plastic clay samples (Plasticity index, PI=76\%) were obtained from a hospital construction site in Ankara, Turkey. The index and reference tests were conducted on untreated soil samples first. The natural clay soils are mixed with the hydrated lime at different percentages of dry weight of the soil $(1 \%, 3 \%, 5 \%, 7 \%$ and $9 \%)$ and compressibility characteristics of the improved soil samples along with the untreated soil characteristics were determined. The compression index $\left(\mathrm{C}_{\mathrm{c}}\right)$ and expansion index $\left(\mathrm{C}_{\mathrm{e}}\right)$ values were calculated with increasing lime content.

It has been concluded that the compressibility of the untreated clay samples are relatively quite high as compared to treated clay's compressibility. Similar conclusion is also valid for unloading part of the odometer tests (i.e. the expansion part). The compressibility of the lime-treated samples decrease substantially starting from 5\% lime content. The $3 \%$ to $5 \%$ lime contents, on the other hand, are quite effective to decrease expansion index. This means that $5 \%$ lime content is the optimum level for both compression and expansion indices to be decreased significantly. 


\section{References}

ASTM D 698 (2007). Standard Test Methods for Laboratory Compaction Characteristics Soil Using Standard Effort $\left(600 \mathrm{kN} / \mathrm{m}^{3}\right)$, American Society Testing Materials.

ASTM D 2435-96 (1996). Standard Test Method for One-Dimensional Consolidation Properties of Soils, American Society Testing Materials.

Eades, J.L., Grim, R.E. (1960). Reaction of Hydrated Lime with Pure Clay Minerals in Soil Stabilization. Bulletin 262, Highway Research Board, Washington, D.C.

Wilson, S.D. (1950). Small Soil Compaction Apparatus Duplicates Field Results Closely. Engineering News Record, Vol. 135, No. 19, pp. 34-36. 